\title{
Design of educational environment for teachers' professional training
}

\author{
Nadiia Balyk, Galina Shmyger, Yaroslav Vasylenko, and Vasyl Oleksiuk* \\ Ternopil Volodymyr Hnatiuk National Pedagogical University, Department of computer sciences and methodology of its teaching, \\ Ternopil, Ukraine
}

\begin{abstract}
The article analyzes the concept of the educational environment, its components and features of the structure. The concept of educational environment design was introduced. The components of educational environment design for the teachers' professional training of the Ternopil Volodymyr Hnatiuk National Pedagogical University (TNPU) are described: technological, didactic and social. The features of this environment such as: information saturation and openness, digital transformation, social practices and cooperation are considered. The study of the effectiveness of educational environment for teachers' professional development was carried out on the basis of TNPU. In total, 432 masters of all specialties of the University participated in this study. The study used the method of expert assessments for statistical processing of results. The study was conducted to determine the level of importance of all indicators of each component of the educational environment design. The results of the study illustrate the significant changes in the technological and social components of the university's educational environment design, which have a significant impact on the teachers' professional training.
\end{abstract}

\section{Introduction}

The key problems of the higher pedagogical school of today are the lack of manifestation of the cultural and historical context for the higher school, which sets the framework for higher education. The rapid development of educational management leads to process-oriented management of an educational institution and the emergence of terms such as "educational space", "educational landscape", "educational field", "educational environment".

Today, there are no universal indicators to quantify and qualify what an effective educational environment is. The new educational perspective on the development of the contemporary educational environment requires the reorganization of many aspects of future teacher training.

The transition from traditional educational models to modern ones envisages a change in the organizational, cultural, institutional dimensions, management models and educational environment design for the teachers' professional training.

\section{Research review}

The analysis of the sources shows that the issues of design and formation of the educational environment are an important component of the training of modern specialists both in Ukraine and abroad.

The educational environment is traditionally defined as learning, which depends on various environmental factors, a set of objective external conditions, factors, social objects. It is a system of influences and conditions of personality formation, as well as opportunities for its development, which are contained in the social and spatial-subject surroundings [1]. The educational environment is a contemporary temporal, spatial and social situation of learning, which consists of many different educational spaces of different levels, which have educational potential and interact in one way or another. In this environment, the interaction of different levels of the education system and personality happens and the corresponding cultural context is also included [2]. As a result of a detailed historical study, scientists of Kherson State University have determined that the most promising model for building an educational environment is a hybrid model [3]. Olena Glazunova and Mariya Shyshkina have been confirmed these findings for the case of university cloud-based learning and research environment [4].

In her monograph Liubov Panchenko determined that modern specialists should be able not only to use, but also to model and create an educational environment [5].

Today, the following structural components of the educational environment are distinguished:

1) physical environment - the room, its design, size and the spatial structure of the training classrooms;

2) human factor - the university contingent structure, its influence on the social behaviour of students, the quality of lecturer training, etc.;

3) training program - the nature of training programs content, technologies of training, style and methods of training, forms of educational activities, the nature of

\footnotetext{
* Corresponding author: oleksyuk@.fizmat.tnpu.edu.ua
} 
control [6]. The components of the educational space are united by certain ideas and values.

The main features of the educational environments that characterize the new millennium have been determined by many researchers [7-9]. They point out that the university's educational environment should include such components as the information and communication environment, the research environment, the organizational and management environment in accordance with the principles of intensity, psychological comfort and democratic possibilities of individualization of learning, openness and accessibility of information resources.

In most foreign studies, the educational environment is described in terms of "educational institution efficiency" as a social system - emotional climate, personal well-being, features of the microculture, quality of the educational process. The educational environment has a significant impact on students' learning and behaviour. There is a strong link between the learning environment and value components such as students' satisfaction and success. The educational environment defines physical and mental self-feeling and motivation and promotes emotional and behavioural responses. The study [10-11] analysed the physical environment using three aspects: the planning and size of study rooms, ergonomics and technology, the informal environment and comfort. Describing the ideal auditorium, students noted the importance of technology and comfort role. A broader understanding of the educational environment supposes the inclusion of various communications (press, radio, television, internet resources) created by young people in their own cultural microenvironment.

The work [12] focuses on the importance of the professional environment of teachers and not only on their professional training. This point should be emphasized, because over the past few years, academic research has forced many experts to assess not only the need to increase teacher effectiveness (for example, through qualification increasing), but also to change the educational environment by improving educational institutions policies, amending laws, and supporting by communities, improving decision-making process, digitizing education that can contribute to quality change in the education sphere.

Modern digitalization means the need to create a new educational environment $[13,14]$. As digital technology becomes a central part of everyday work, teachers are forced to rethink and transform previous educational traditions through technology. These problems create insurmountable requirements for universities to develop teachers' professional training strategies in the context of mastering digital pedagogy and the digital educational environment [15-18].

\section{Results and discussion}

\subsection{The structure of educational environment}

During the research the following methods were used: analysis of scientific and methodological and technical literature in the field of educational environments design, state standards of higher education. In the course of the experimental research, the methods of observation, questioning and expert assessments were applied. The questioning of the respondents was conducted according to the methodology of expert assessments, with further processing of its results using the methods of mathematical statistics.

Analysing the views of various scientists about the particularities of the educational environment [19-21], we introduce the concept of educational environment design as a way of integrating and adopting many of its dimensions. In our study, as the concept of "design of the university's educational environment" we will consider systemic formation, which is a sociocultural surroundings of the subject of learning, which includes technological, didactic, social components that are able to provide quality professional training for teachers.

Such subjects (involved in the process of creating educational values) as lecturers, students, undergraduates, graduate students, educational institutions, organizations, scientific centres are important in the design of the university's educational environment for teachers' professional training.

Let us consider the components of the educational environment which were forming at the TNPU in recent years in the context of teachers' professional training.

The technological component of the educational environment design for teachers' professional training was provided through the creation of a digital environment for the university. The University's digital environment infrastructure is a system of software, computing and telecommunications tools that implements the providing of information, computing, telecommunication resources and services to all participants in the educational process. Various tools have been integrated into the university's digital environment, which enrich the educational process. In terms of infrastructure this environment is based on the use of university's LMS, cloud-based learning environment (CBLE), university's digital repository, Web 2.0 services. The researchers Olena Kuzminska, Mariia Mazorchuk, Nataliia Morze, Oleg Kobylin found 4 main components that group all the factors of the digital educational environment into such areas of focus as IT infrastructure and resources' provision, students' and teachers' digital competencies, scientific and educational communication between the students, teachers, and stakeholders, and educational process organization [22].

The effectiveness of CBLE in teaching and research has been investigated and tested by Ukrainian scientists under the guidance of Oleg Spirin [23], [24].

We consider that indicators of technological component development are:

1) University network and Internet access. TNPU provides access for students and lecturers from anywhere on campus to the resources of educational environment and the Internet. Local wired and wireless technologies have been used for this purpose. All resources are accessed using a single authentication data.

2) Learning Management System and courses. An advanced learning management system is functioning at the university. All subjects that are studying by students 
have relevant e-courses in this system. In total, more than 600 courses have been developed by lecturers. Practically all kind of students' activities are recorded in this system.

3) Cloud services and laboratories. Since 2012, the lecturers of Computer Sciences Department and Methodology of Its Teaching have been working on the deployment of a cloud-oriented learning environment. It now operates according to a hybrid model and integrates many services of public and private platforms. CBLE provides unified, ubiquitous and secure access to file and computing resources (repositories, virtual computers, and networks). Cloud infrastructure provides management of educational resources, aggregation of computing resources, knowledge sharing services, increasing the flexibility of their use by participants in the educational environment.

4) Hardware for 3D design and printing. Within the frame of work of STEM-centre [25] promising technologies of 3D-modeling and 3D-printing, technologies of virtual and augmented reality, technologies of the Internet of things, robotics are being implemented at the University. These technologies ensure the execution of innovative projects through the formation of tool environments, the use of project management services. Work on educational projects (for example, a project on 3D-reconstruction and 3D-printing of the destroyed historical castles of Ternopil region) takes place inside a technologically equipped modern educational environment.

5) Open environment. An open, non-formal learning environment with lecturers and students has created at the University. The traditional academic hierarchy is gradually being replaced by an approach where students are respected as junior colleagues, and their opinions are appreciated and encouraged by more experienced colleagues. Such teaching is based on modern didactic approaches such as personality-oriented and synergistic. The technological basis of open education at TNPU is modern digital technologies, in particular cloud. This approach encourages dialogue and collaboration between students and lecturers, and creates new opportunities for the development of up-to-date professional training for future teachers.

6) University archives and repositories. The University has implemented a system of digital archives. The TNPU Institutional Repository contains materials published by lecturers, such as: monographs, books, manuals, articles, abstracts. Some faculties have digital archives for educational purposes. In addition to the materials of lecturers, they contain the results of students' learning - materials of practices, articles of students, master's works, etc.

Among the important components of the educational environment design of the university should be distinguished didactic, which includes the structure of students' activities, teaching style, nature of control, forms of study, the content of study programs. For example, the professorial and teaching staff of TNPU pays special attention to the modernization of educational programs in the context of the tasks of the New Ukrainian School through:
- implementation of a competency, personality-oriented approach in pedagogical education;

- formation of managerial skills for effective activity in the conditions of real autonomy of educational institutions;

- providing practical training through continuous pedagogical practice of students at different educational institutions.

In TNPU, the didactic component of the educational environment design for future teachers' professional training is characterized by digital transformation, student-centred education; using:

- thematic project studies;

- critical thinking;

- group work;

- social practices.

Let's take a closer look at these efficiency indicators of the didactical component for educational environment design:

1) Digital transformation. The digital transformation of the university's educational environment is a series of coordinated steps and changes in the information infrastructure, in the digital culture of lecturers and students. This makes it possible to embody new educational models and transform the activities of the university, aiming at value propositions and strategic directions for the development of modern society.

2) Group work. Group work is characteristic of many university disciplines. Its purpose is for students to practice teamwork in small groups, as well as to develop problem-solving and leadership skills. Group work is an important aspect of future teacher training with aim of real professional situations modelling.

3) Critical thinking. Critical thinking is encouraged in all activities at the university. At seminars, workshops, laboratory work the students analyse and present solutions to problems and tasks. Theoretical concepts are tested in practical situations, and practical experience is used to develop and enrich the theory.

4) Student-centred education. Studying at TNPU is student-centred. There is great support from educators, lecturers play the role of facilitators, helping students understand the content of the course. The focus is on giving students the opportunity to develop their critical and analytical thinking skills, self-study, group work, problem-solving and leadership skills to prepare them for careers.

5) Thematic project studies. The teaching methods used in university study focus on critical analysis of course content using real cases where possible. Invited teachers and speakers from schools, local authorities, and public organizations participate in the educational program to further link research with the professional environment.

6) Pedagogical practices. Much of the learning process takes place outside the classroom when students apply acquired professional competencies in real-life situations while undergoing pedagogical practices. Learning technologies are partly beyond the bound of university classrooms.

Let us characterize the indicators of the effectiveness of the social component of design of the modern 
educational environment of teacher training of the TNPU in the context of exploring ways of improving their professional development.

It is traditionally considered that university education is constructed based on the context of the surrounding reality, the cultural space and the environment in which the education takes place. Therefore, at TNPU the main indicators of the effectiveness of design of the modern educational environment of teacher training in the social aspect are: social innovation, leading development, corporate culture, leadership, social partnership, and social communication:

1) Social innovation. n our opinion, the departure from the traditional functions of TNPU and the implementation of innovative ones became important for the professional development of teachers:

- creation of conditions for the system of qualitative training and professional development of teachers through overcoming the fragmented responsibility of different educational institutions for different stages of becoming and professional development of the educator; - transition from "translational" education to "active" based on the implementation of digital technologies, project and competency learning technologies.

2) Leading development. The essence of leading-edge development lies:

- in building curricula and learning programs around cross-cutting topics relevant to a particular public community, a united territorial community;

- in preparing graduates to organize the life of their local community in accordance with the principles of sustainable and successful development.

3) Corporate culture. We consider that not only structural components are the social component achievement of the university's educational environment design, but first of all - corporate culture. The key factor to the success of university education transformation projects has been the formation of a collective subject for change. The corporate culture of the university is based on a system of values that determine the philosophy of its activity, the attractiveness of the university brand in the scientific, educational and contemporary socio-cultural environment.

4) Social leadership. Social leadership means:

- engraftment of innovation as a way of thinking and a key leadership tool;

- distributed leadership in the development of new educational decisions and educational reforms,

- formation of teachers, as educators of leaders of the new generation, integral personalities.

The University promotes the growth of students as individuals through quality professional training of highly qualified professionals and personal growth.

5) Social partnership. TNPU's educational environment design serves as a catalyst for a new social reality in the region. The University is an active social partner and an element of the social system. The collaboration and partnership of the university's educational environment with various actors of the educational field and the public is developing. Lecturers share knowledge and experience in the educational environment, give the products of their professional and innovative activities in the public usage, participate in volunteer activities, assessments and expertise, and more.

6) Social communication. Communication has become a key prerequisite for the creation of new meanings, ideas and projects of the University, organization of applied research at the request of regional companies, authorities and the local community. It is important that the university is open to industry, government and other stakeholders. We believe that the greater the degree of openness of a university, the better it develops. The University successfully builds all necessary for its own existence and development of communications with other entities - authorities, manufacturing companies, civil society institutions.

\subsection{The study on the effectiveness of educational environment design}

In order to determine the effectiveness of the created educational environment design for the teachers' professional development in $2017 / 2019$, a study was conducted in the form of a survey among future teachers. 432 masters of all pedagogical specialties of the University participated in the survey. We viewed undergraduates as internal stakeholders.

The questionnaire suggested to assess the importance of development each component of the university's educational environment design. In each component we have identified indicators of its development (see Table 1).

Table 1. List of indicators for assessment of the components of the university's educational environment design.

\begin{tabular}{|c|c|c|}
\hline $\begin{array}{c}\text { Component of the } \\
\text { educational } \\
\text { environment }\end{array}$ & $\begin{array}{l}\text { Cipher of } \\
\text { indicator }\end{array}$ & $\begin{array}{c}\text { The name (description) of } \\
\text { the indicator }\end{array}$ \\
\hline \multirow{6}{*}{ Technological } & $\mathrm{T} 1$ & $\begin{array}{l}\text { University network and } \\
\text { Internet access }\end{array}$ \\
\hline & $\mathrm{T} 2$ & $\begin{array}{l}\text { Learning Management } \\
\text { System and courses }\end{array}$ \\
\hline & $\mathrm{T} 3$ & \begin{tabular}{|ll}
$\begin{array}{l}\text { Cloud services and } \\
\text { laboratories }\end{array}$ & \\
\end{tabular} \\
\hline & $\mathrm{T} 4$ & Open environment \\
\hline & T5 & $\begin{array}{l}\text { Hardware for 3D design and } \\
\text { printing }\end{array}$ \\
\hline & T6 & $\begin{array}{lll}\begin{array}{l}\text { University archives and } \\
\text { repositories }\end{array} & & \\
\end{array}$ \\
\hline \multirow{6}{*}{ Didactic } & D1 & Digital transformation \\
\hline & D2 & Group work \\
\hline & D3 & Critical thinking \\
\hline & D4 & Student-centred education \\
\hline & D5 & Thematic project studies \\
\hline & D6 & Pedagogical practices \\
\hline \multirow{6}{*}{ Social } & S1 & Social innovation \\
\hline & $\mathrm{S} 2$ & Leading development \\
\hline & S3 & Corporate culture \\
\hline & S4 & Social leadership \\
\hline & S5 & Social partnership \\
\hline & S6 & Social communication \\
\hline
\end{tabular}

In each questionnaire, we explained to the experts the value of each indicator. To determine the most significant indicators of educational environment development, we used the ranking method. It was to 
determine the relative importance of the objects under study based on their ordering. A scoring system for assessment was proposed for each component. In each component of the educational environment development, the experts gave points. One point was awarded to the least significant indicator and six points to the highest significant one. The results of the survey are summarized in a table, the columns of which correspond to the codes of indicators, and in rows - sequence numbers of experts (see Table 2). The table data can be viewed in its entirety by the hyperlink:

https://drive.google.com/file/d/1YHaqVE0NSVktz9Glw zqGVGy2HAK7CDWy/view?usp=sharing

Table 2. The final results of the study data processing.

\begin{tabular}{|c|c|c|c|c|c|c|c|c|c|c|c|c|c|c|c|c|c|c|}
\hline & \multicolumn{6}{|c|}{ Technological } & \multicolumn{6}{|c|}{ Didactic } & \multicolumn{6}{|c|}{ Social } \\
\hline \multirow{2}{*}{ Expert } & \multicolumn{18}{|c|}{ Indicators } \\
\hline & $\mathrm{T} 1$ & $\mathrm{~T} 2$ & T3 & $\mathrm{T} 4$ & T5 & T6 & D1 & D2 & D3 & D4 & D5 & D6 & S1 & $\mathrm{S} 2$ & S3 & S4 & S5 & S6 \\
\hline 1 & 5 & 6 & 3 & 4 & 1 & 2 & 6 & 5 & 1 & 4 & 2 & 3 & 6 & 5 & 1 & 4 & 2 & 3 \\
\hline 2 & 6 & 5 & 4 & 3 & 1 & 2 & 6 & 4 & 5 & 1 & 3 & 2 & 6 & 3 & 4 & 1 & 5 & 2 \\
\hline & & & & & & & & & & & & & & & & & & \\
\hline 432 & 6 & 5 & 4 & 3 & 1 & 2 & 4 & 5 & 6 & 1 & 2 & 3 & 6 & 4 & 1 & 5 & 3 & 2 \\
\hline$S_{j}$ & 2394 & 1946 & 1573 & 1405 & 770 & 984 & 2368 & 2153 & 1300 & 1119 & 969 & 1164 & 2369 & 1682 & 750 & 1736 & 1593 & 934 \\
\hline$d_{j}$ & 882 & 434 & 61 & -107 & -742 & -528 & 856 & 641 & -212 & -393 & -543 & -348 & 857 & 170 & -762 & 224 & 81 & -578 \\
\hline$S\left(d^{2}\right)$ & \multicolumn{6}{|c|}{1810798} & \multicolumn{6}{|c|}{1758963} & \multicolumn{6}{|c|}{1734814} \\
\hline$W$ & \multicolumn{6}{|c|}{0.55445265} & \multicolumn{6}{|c|}{0.539} & \multicolumn{6}{|c|}{0.53118692} \\
\hline
\end{tabular}

In order to prevent psychological clues that could influence the expert's choice of a certain ranking order, indicators of a certain criterion in the card were placed in alphabetical order.

An expert assessment method was chosen to work out the results of the survey, which was applied to each component of the university's educational environment individually due to the independent ranking of indicators within each component.

The most obvious value of assessment an indicator is its total rank, which is determined by all experts ( $S_{j}=\sum_{i=1}^{m} R_{i j}$, where $R_{i j}$ is the $j$-th indicator exhibited by the $i$-th expert, $m$ is the number of experts).

However, such aggregate rankings will be objective if there is a certain level of agreement between the experts. The degree of such agreement is described by Kendall's coefficient of concordance $W$ [26], which is defined as follows:

1. For each indicator, we find the difference between the totals and their average:

$$
d_{j}=\sum_{i=1}^{m} R_{i j}-0.5 \cdot m \cdot(n+1)
$$

2. Find the sum of squares of values obtained from relation (1) $S\left(d^{2}\right)$

$$
S\left(d^{2}\right)=\sum_{i=1}^{n} d_{j}^{2}=\sum_{i=1}^{n}\left[\sum_{j=1}^{m} R_{i j}-0.5 \cdot m \cdot(n+1)\right]^{2}
$$

3. The maximum value of $S\left(d^{2}\right)$

$$
S_{\max }\left(d^{2}\right)=\frac{1}{12} \cdot m^{2}\left(n^{3}-n\right)
$$

is achieved if all experts rank the criteria (indicators) equally.

4. The coefficient of concordance is equal:

$$
W=\frac{S\left(d^{2}\right)}{S_{\max }\left(d^{2}\right)}=\frac{12 \cdot S\left(d^{2}\right)}{m^{2}\left(n^{3}-n\right)}
$$

According to formulas (1) - (3) we find the values of the total ranks $S_{j}$, the values $d_{j}, S\left(d^{2}\right)$ and calculate the coefficient of concordance $W$ for each component of the educational environment. The results of the calculations are presented in Table 2 .

This value is always between zero and one. If $W=0$, then there is no correlation between expert rankings, if $W=1$, then the rankings are completely the same. We get the coefficient $W=0.55 ; 0.54 ; 0.53$ is substantially different from zero, so it can be argued that there is objective agreement between experts.

However, such a value of $W$ is not a criterion for objectivity, since it could be obtained by accidentally setting of ranks one or the other indicators.

The value $m \cdot(n-1) \cdot W$ is distributed by the law $\chi^{2}$ with $n$-1 degree of freedom. Using the ratio

$$
\chi_{W}^{2}=\frac{12 \cdot S\left(d^{2}\right)}{m \cdot n(n+1)}
$$

we find the value of $\chi_{W}^{2}=1197.62 ; 1187.77 ; 1147.36$ for the relevant components of the educational environment. Comparing them with the table value for $\vartheta=n-1=5$ degrees of freedom and for the significance level of $\alpha=0.01$, we obtain $\chi_{W}^{2}>\chi_{t}^{2}=15.1$. Hence, we conclude that there is consistency between experts' findings.

Consider the results of the survey regarding the importance of technological, didactic and social components of the university's educational environment design for teachers' professional development of teachers of the pedagogical university (see Figures 1-3).

From the conducted study it follows that: - of the technological component, the most important for the teachers' professional development are University network and Internet access, Learning Management System and courses, Cloud services and laboratories; - of the didactic component most important for the teachers' professional development are Digital transformation, Group work, Critical thinking; - of the social component the most important for the teachers' professional development teachers are Social innovation, Social leadership, Leading development. 


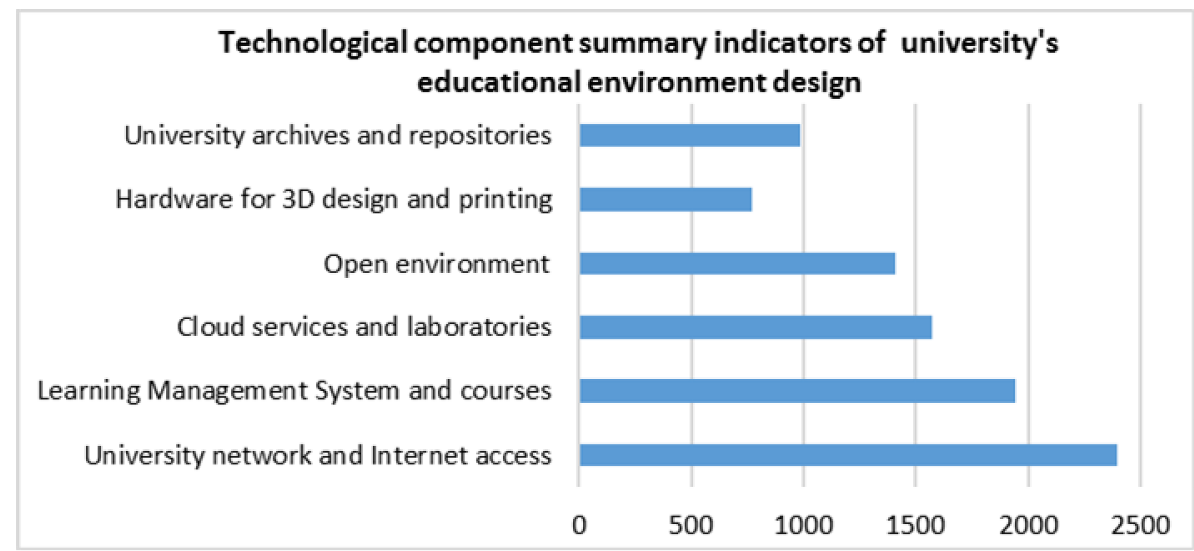

Fig. 1. Study's results of technological component importance of university's educational environment design of in the context of teachers' professional development.

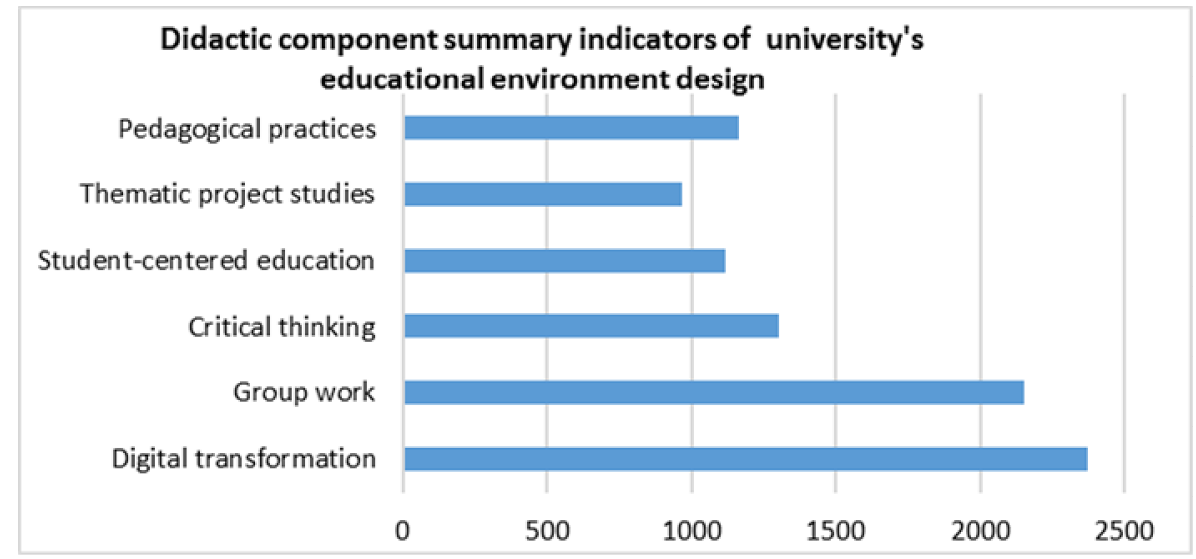

Fig. 2. Study's results of didactic component importance of university's educational environment design of in the context of teachers' professional development.

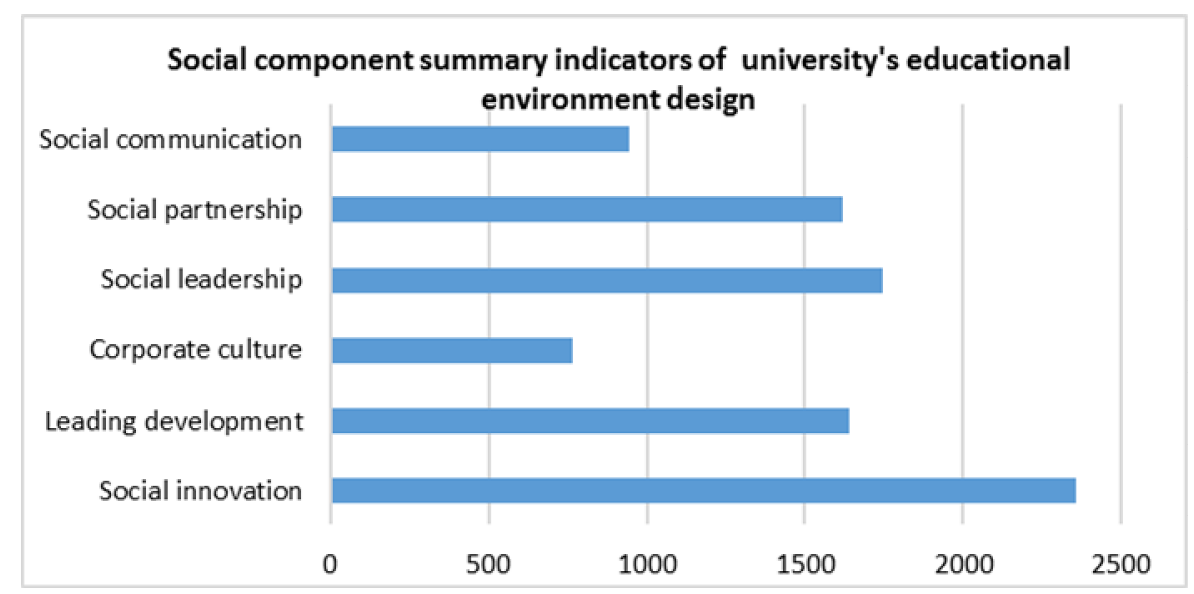

Fig. 3. Study's results of social component importance of university's educational environment design of in the context of teachers' professional development.

To determine the significance degree of each component of the educational environment, we calculated the arithmetic mean of the scores for each indicator (see Table 3). The indicator was considered positive if the arithmetic mean of expert estimates was at least 3.0.

The significance degree of each component was determined as follows:
- not significant enough - more than $50 \%$ of the criteria are negative;

- critically significant $-50 \%$ - $55 \%$ of the criteria are positive;

- significant enough $-56 \%-75 \%$ of the criteria are positive;

- highly significant $-76 \%-100 \%$ of the criteria are positive. 
Table 3. Significance degrees of the university's educational environment.

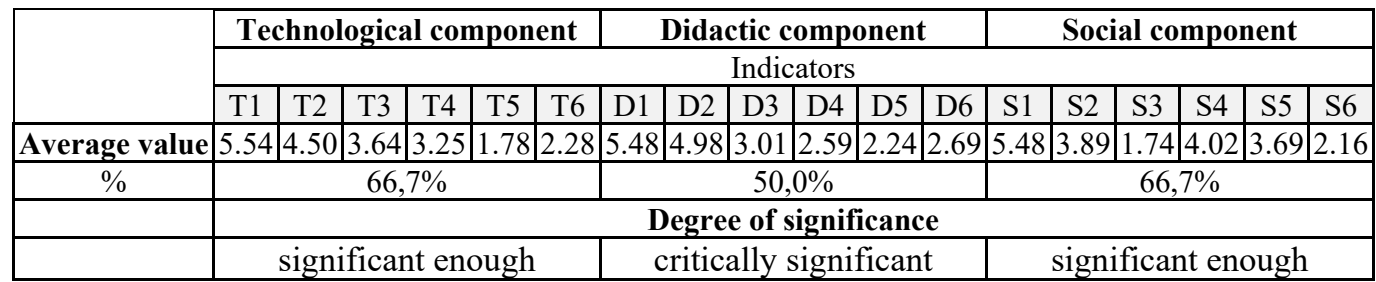

From the conducted study it follows that at the TNPU over the past three years, according to the view of undergraduates, technological and social components of the educational environment design have become crucial for teachers' professional development.

\section{Conclusions}

An analysis of the literature indicates that the term "educational environment" has no unambiguous interpretation. The study proposes to define the design of the educational environment as a systemic formation, which includes technological, didactic, social components that are able to provide quality professional training for teachers.

It should be noted that the design features of the modern educational environment of the TNPU are: openness and information saturation, student-centred education, thematic project studies, social practices, a harmonious blend of pedagogy and digital technology and, as a result, the digital transformation of educational environment design.

To identify the effectiveness of the created design of the university's educational environment for the teachers' professional development the components of their formation and their corresponding indicators were determined. In the process of research, the undergraduates noted that the greatest influence on their professional development has social (Social innovation, Social leadership and Leading development) and technological component of the educational environment design (University network and Internet access, Learning Management System and courses, Cloud services and laboratories).

We consider that in the development of educational environment design of pedagogical university promising directions are such as:

- developing educational strategies and monitoring their implementation and effectiveness;

- realization by the university of its socially transformative role - social and humanitarian innovations, humanitarian paradigm of education;

- organizing effective interaction between the university and external players in order to attract investments to create quality conditions for learning and nurturing successful and competitive human capital.

The perspectives of further research are in experimental testing the designed environment by other internal and external stakeholders like as lecturers, teachers, developers, IT-managers etc.

\section{References}

1. R. Hiemstra, Aspects of effective learning environments. New Directions for Adult and Continuing Education 50, 5-12. (1991). doi:10.1002/ace.36719915003

2. H. Mandl, G. Reinmann-Rothmeier, in International encyclopedia of the social and behavioral sciences, ed. by N.J. Smelser, P.B. Baltes (Elsevier, 2001), pp. 4697-4701

3. A. Spivakovsky, L. Petukhova, V. Kotkova, Yu. Yurchuk, Historical Approach to Modern Learning Environment. CEUR Workshop Proceedings 2393 (2019), http://ceur-ws.org/Vol2393/paper_420.pdf Accessed 22 Dec 2019

4. O. Glazunova, M. Shyshkina, The Concept, Principles of Design and Implementation of the University Cloud-based Learning and Research Environment. CEUR Workshop Proceedings 2104 (2018), http://ceur-ws.org/Vol-2104/paper_158.pdf Accessed 22 Dec 2019

5. L.F. Panchenko, Information and educational environment of the modern university ("LNU named after Taras Shevchenko", Luhansk, 2010)

6. Analitychnyi zvit pro virtualnyi kruhlyi stil «Yak zdiisniuvaty upravlinnia seredovyshchem vzaiemodii usikh uchasnykiv osvitnoho protsesu?» (Virtual Roundtable Analytical Report "How to manage the interaction environment of all participants in the educational process?") (2017), http://education-ua.org/ua/draft-regulations/966analitichnij-zvit-pro-virtualnij-kruglij-stil-yakzdijsnyuvati-upravlinnya-seredovishchemvzaemodiji-usikh-uchasnikiv-osvitnogo-protsesu. Accessed 25 Dec 2019

7. OECD, Creating Effective Teaching and Learning Environments: First Results from TALIS. Executive summary https://www.oecd.org/berlin/43024880.pdf. Accessed 27 Dec 2019

8. A. M. Kalimullin, Z. I. Islamova, Formation of Information-Educational Environment in the Partner Universities of University of Shanghai Cooperation Organization. IEJME 11(6), 1879-1890 (2016)

9. A. Potter, Powerful Learning Environments: Unravelling Basic Components and Dimensions. Internet and Higher Education 7, 154-157 (2004). doi:10.1016/S1096-7516(04)00020-X 
10. L. Licite, L. Janmere, in Engineering for rural development, Jelgava, 23-25.05.2018, pp. 11981203. doi:10.22616/ERDev2018.17.N361

11. C. Anderson, K. Day, Purposive environments: engaging students in the values and practices of history. IJHEEP 49(3), 319-343 (2005)

12. Standards of Professional Competencies Required of Teachers (2011), http://cfieleon.centros.educa.jcyl.es/sitio/upload/mo delo_competencias_profesionales_profesorado $\% 20$ traducido.pdf. Accessed 20 Dec 2019

13. O. E. Hatlevik, K. A. Christophersen, Digital competence at the beginning of upper secondary school: Identifying factors explaining digital inclusion. CE 63(1), 240-247 (2013)

14. A.E. Kiv, V.N. Soloviev, S.O. Semerikov, How cloud technologies continues to transform education. CEUR Workshop Proceedings 2433, 119 (2019), http://ceur-ws.org/Vol-2433/paper00.pdf. Accessed 20 Dec 2019

15. Digitalisation strategy for the higher education sector 2017-2021 (2017), https://www.regjeringen.no/contentassets/779c0783 ffee461b88451b9ab71d5f51/en$\mathrm{gb} / \mathrm{pdfs} /$ digitaliseringsstrategi-for-uh-sektorenengelsk-ve.pdf. Accessed 20 Dec 2019

16. J. Howell, Teaching With ICT: Digital Pedagogies For Collaboration And Creativity (Oxford University Press, Melbourne, 2012)

17. C. Kivunja, Embedding Digital Pedagogy in PreService Higher Education To Better Prepare Teachers for the Digital Generation. IJSHE 2(4), 131-142 (2013). doi:10.5430/ijhe.v2n4p131

18. J. Stommel, Critical digital pedagogy: A definition. Hybrid Pedagogy (2014). http:/www.digitalpedagogylab.com/hybridped/criti cal-digital-pedagogy-definition. Accessed 8 Dec 2019

19. A. Lund, T. E. Hauge, Designs for Teaching and Learning in Technology Rich Learning Environments. NJDL 4, 258-271 (2011)

20. W. Roth, Learning environments research, lifeworld analysis, and solidarity in practice. LER 2(3), 225247 (1999). doi:10.1023/A:1009953920993

21. K. Day, Creating and Sustaining Effective Learning Environments. AISHE-J 1(1), 1-13 (2009)

22. O. Kuzminska, M. Mazorchuk, N. Morze, O. Kobylin, Attitude to the Digital Learning Environment in Ukrainian Universities. CEUR Workshop Proceedings 2393 (2019), http://ceurws.org/Vol-2393/paper_245.pdf. Accessed 22 Dec 2019

23. O. Spirin, Yu. Nosenko, A. Iatsyshyn, Current requirements and contents of training of qualified scientists on information and communication technologies in education. Information technology and learning tools 56(6), 219-239 (2016)
24. O. Spirin, V. Oleksiuk, O. Oleksiuk, S. Sydorenko, The Group Methodology of Using Cloud Technologies in the Training of Future Computer Science Teachers. CEUR Workshop Proceedings 2104 (2018), http://ceur-ws.org/Vol2104/paper_154.pdf. Accessed 20 Dec 2019

25. N. Balyk, G. Shmyger, Y. Vasylenko, V. Oleksiuk, A. Skaskiv, in E-learning and STEM Education, ed. by E. Smyrnova-Trybulska (Studio NOA, Katowice, 2019), pp. 109-125

26. P. Legendre, in Encyclopedia of Research Design, vol. 1, ed. by N.J. Salkind (SAGE Publications, Los Angeles, 2010), pp. 164-169 